not before. Even so it is not without interest to proceed on hypothetical lines because it is the experience of every curator that certain objects prove intractable. It might be supposed, for example, that continual swelling and shrinking prevents embrittlement in organic materials. Another possibility is connected, not unreasonably, with gradients in moisture content within the object. Certain forms of deterioration in paintings (both panel and canvas) can be shown undoubtedly to result from the gradient set up when the back is in close proximity to what may be a cool and/or damp wall, while the front enjoys constant and ideal but different conditions. It cannot be assumed that such steady-state conditions are a priori more favourable on all counts than cyclic ones in which even a reversal of the gradient is possible. The transfer of soluble material, whether salts or adhesives, within the object is a souree of breakdown, particularly at an interface where the structure is laminar. The report does not deal with this phenomenon beyond pointing out that the varia. tion in climate within a room may be such as to produce a 12 per cent variation in relative humidity over $3 \mathrm{~m}$. in height. The importance of moisture content gradients relative to the main hazard-the swelling and shrinking of hydrophilic gels-is a matter for investigation. The result may well explain the unexpected results of air-conditioning which sometimes disappoint the curator. In so many investigations connected with conservation the actual number of variables is difficult to define, and generalizations are often misleading. A case in point is the assumption (p. 247) that picture canvases become slack when the atmosphere is over-dry, as raw natural fibre textiles do. The converse is more often observed because the textile behaviour is opposed by that of the animal glue with which it is impregnated-old masters made use of this effect to tension their canvases.

The report is generously illustrated with diagrams, photographs of instruments and conditioning apparatus, and with striking examples of objects which have suffered deterioration due to unfavourable environment.
S. REeS Jones

\title{
VIEWING AND LISTENING
}

A YEAR ago the British Broadcasting Corporation published a report of an audience research inquiry under the title The Public and the Programmes. The interest which this aroused has encouraged the Corporation to make available other findings of its Audience Research Department. Facts and Figures about Viewing and Listening* offers, in a series of twelve charts, some facts which are important to a proper understanding of what has been happening to viewing and listening habits in recent years.

Each chart has its accompanying commentary explaining the significance of the matter dealt with and directing attention to outstanding points.

Charts I and II show the extent to which the British public uses the three broadcasting services, BBC Sound, BBC-TV and ITV. This is assessed in two ways-in terms of the numbers who typically listen (or view) in the course of a single day (that is, the numbers of 'patrons'), and in terms of the average number who are listening (or viewing) at any given moment (that is, the 'average audience').

Chart I, "The Patronage of Broadcasting", shows the number of adult 'patrons' for each service quarter by quarter for the past three years and shows that the number of adult patrons of BBC Sound has not fluctuated very greatly (this, despite the continuing increase in television coverage). The numbers of adult patrons of both BBC-TV and ITV have shown a rising tendency, with a seasonal fluctuation. The number of BBC-TV adult patrons is consistently above that of ITV because, if for no other reason, though all viewers can see BBC-TV, some cannot vet receive ITV.

The curves for child-patrons show that a much smaller proportion of children than adults patronize Sound and a larger proportion of children patronize ITV than patronize BBC-TV.

In Chart II a different picture emerges when the services are compared in terms of 'average audience' than when they are compared in terms of 'patrons'.

* British Broadcasting Corporation. Facts and Figures about Viewing and Listening. In Twelve Charts with a Commentary. Pp.
Thus, Sound's patrons exceed those of either television service, but its average audience is much smaller than that of BBC-TV or ITV. The explanation lies in the fact that the average patron of sound listens for a relatively small proportion of the time during which sound broadcasting is transmitted. Similarly, though there are more patrons of BBC-TV than of ITV, the former spend less time viewing ( $1 \mathrm{hr} .44$ min. a day) than do the latter ( $2 \mathrm{hr} .12 \mathrm{~min}$.); hence the number who are viewing ITV at any given moment $(7,500,000)$ is greater than the number who are viewing $\mathrm{BBC}-\mathrm{TV}(6,350,000)$.

Chart III shows the relationship, since 1952-53, between the amount of time (in the evening) during which television programmes were broadcast and the amount of time which the average viewer actually spent in viewing. Two points emerge from this comparison: (1) that an increase in the number of television programme hours in the evening is not followed by a proportionate increase in viewing; (2) that, since commercial television became available, there has been little difference between the amount of time spent in evening viewing by those who could receive both $\mathrm{BBC}$ and ITV and by those who could only receive BBC-TV.

These results suggest that the introduction of further television services (a third and perhaps a fourth) will be unlikely to cause an increase in the total amount of time which people devote to viewing.

Charts IV and V illustrate the way in which people with multichannel receivers distribute their viewing between BBC-TV and commercial television. Chart IV shows the proportions which, on the average day in each quarter of the past two years, confined their viewing to BBC-TV, viewed both BBC and ITV, confined the viewing to ITV, or did not view at all. The last of these categories tends to vary seasonally, being greatest in the July-September quarter. Apart from this, there has been a tendency in the past two years for fewer adults to confine their viewing to ITV and for considerably more to view both services. Among children, many more restrict their viewing to ITV than restrict it to BBC-TV. 
Chart $\mathrm{V}$ shows how Band $1 / 3$ viewers have divided their evening viewing time between $\mathrm{BBC}$ and commercial television. The trends are remarkably similar: when commercial television first comes to a region there is usually a period of 'settling down' during which the proportion of time given to BBC-TV tends to fall. Then relative stability is reached.

Chart VI relates to the way evening viewing is divided between BBC and ITV according to the educational level of the viewer. Among those whose full-time education continued up to and beyond the age of seventeen years, roughly half view BBC-TV either virtually exclusively or more than they view Independent Television. Those in this group who view ITV exclusively or predominantly are a minority, 37 per cent. In the group whose fulltime education was not continued beyond the age of fifteen or sixteen, about 30 per cent either always view $\mathrm{BBC}$ or view it more than ITV, whereas 52 per cent, always or more often, view ITV. In the group whose full-time education ceased at fourteen years or earlier the corresponding proportions are 20 per cent and 65 per cent respectively.

Chart VII shows the present comparative quantities of listening to sound broadcasting at different times of the day. The period when there is most listening is shown to be that between noon and 2 p.m. when the average audience is nearly 5.5 million. The main point brought out by the chart is that 'levels' of listening in the afternoon and evening are now far lower than those in the morning; in the evening sound broadcasting must compete with television.

The 1950-60 trends in the day-time and evening audiences for sound are shown in Chart VIII. During the period 6-11 p.m. Sound's audiences declined sharply each year with the result that, for every four people who were listening in January-March 1950, only one was doing so ten years later. Between 9 a.m. and 6 p.m., on the other hand, when the competition of television was less fierce, audiences for sound showed no comparable decrease. For every four people listening in the winter of 1950 , three were doing so ten years later.

Chart $\mathrm{X}$ shows how much time 'listeners' and 'viewers' have spent with sound broadcasting in the evening each autumn since 1954. The average adult 'listener', far from reducing his evening listening, has tended to increase it in the past six years. He now listens for about $1 \mathrm{hr}$. (out of a possible 5) a night. The average 'viewer', on the other hand, has never listened much in the evening. This small average quantity of listeners guarantees Sound broadcasting a considerable audience in the evening. Even if the time should come when virtually everyone has a television set, the audience for sound broadcasting in the evening would still, at this rate of "viewerlistening', be about one million persons.

Chart XI shows the extent to which, during October-December 1960, children aged five to seven, eight to eleven, and twelve to fourteen years viewed television between 5 and $6 \mathrm{p.m}$. and in the first half of the evening, 6-9 p.m. Each day between the hours of 5 and 9 p.m. the average child of five to seven years and the average child of eight to eleven years, watched television for more than two hours, while the average twelve to fourteen-year-old watched for nearly an hour and a half-and in each case the bulk of this time was spent in viewing programmes after 6 p.m.

Between 5 and 6 p.m., the older the child the greater is the share of such time when he views which he devotes to BBC-TV. During the early evening, on the other hand, the reverse is true: the older the child the smaller is the share of his viewing time which he spends with BBC-TV.

Chart XII shows that the size of an audience is, by itself, no sure guide to its popularity. The Chart illustrates this by showing that, during four typical weeks in mid-winter 1960 , there were fourteen BBC-TV broadcasts each of which had an audience numbering approximately six million persons yet varied widely in the extent to which they were enjoyed. At one extreme one broadcast had a reaction index (the BBC's yardstick of 'enjoyment') of seventy-nine (out of a possible one hundred), while at the other was one with a reaction index of forty-nine. Thus, had 'audience size' alone been accepted as the criterion of popularity, these two broadcasts would have ranked as equal, whereas it is clear that those who saw Broadcast No. 1 enjoyed it far more than those who saw Broadcast No. 14.

\section{EDUCATION OF BACKWARD CHILDREN IN BRITAIN}

GINCE the War there has been a three-fold increase $S$ in the number of places available in special schools in Britain for educationally sub-normal children, the figure having risen from 11,000 in 1946 , to 34,500 at the beginning of this year.

Educationally sub-normal pupils are defined as "pupils who, by reason of limited ability or other conditions resulting in educational retardation, require some specialized form of education wholly or partly in substitution for the education normally given in ordinary schools". They form one of ten categories of handicapped pupils for whom special education is provided. There is no overall national deficiency of places for blind, partially sighted, deaf, partially deaf, epileptic, physically handicapped, delicate and speech-defective children, although for some of these handicaps local improvements can be and are being made.

In a circular to local education authorities (11/61) Sir David Eccles, Minister of Education, estimates that a further 19,500 places will be needed to cater fully for all the educationally sub-normal children requiring education in special schools.

The Minister has already announced building programmes for the years up to March 1963 to provide about 10,000 of the places and intends to approve programmes, as soon as practicable, to provide the remainder.

The circular discusses the role of parents, teachers and doctors in discovering backwardness among children and in assessing their needs and the various measures that may be taken to enable them to live useful and independent lives. There has been a substantial increase in the rate at which children are brought forward for assessment since the War, during which time the school population has risen from 5 million in 1946 to 7 million in 1961

Backwardness may be due to limited ability or other causes such as illness, a break in schooling or a disturbed home background. Many of these children 